\title{
Nitric Oxide and Thermogenic Function of Brown Adipose Tissue in Rats
}

\author{
Shyamal Kumar SAHA and Akihiro KUROSHIMA \\ Department of Physiology I, Asahikawa Medical College, Asahikawa, 078-8510 Japan
}

\begin{abstract}
To clarify the effects of cold acclimation and immobilization stress adaptation of rats on nitric oxide (NO) activity in interscapular brown adipose tissue (BAT), we incubated neatly diced (1- $\mathrm{mm}^{3}$ blocks) BAT in a metabolic chamber for respiration, measured oxygen consumption using a Clark electrode, and estimated NO release in the buffer medium by measuring nitrite plus nitrate $\left(\mathrm{NO}_{x}\right)$ using the Griess method (diazotization reaction). The production of $\mathrm{NO}_{x}$ in the buffer medium confirmed that BAT releases NO, as there is no other source of $\mathrm{NO}_{x}$ in the system.
\end{abstract}

The NO activity was observed in the basal condition and increased with noradrenaline stimulation, showing a correlation with oxygen consumption in the warm $\left(25^{\circ} \mathrm{C}\right)$-acclimated control rats. Cold acclimation $\left(5^{\circ} \mathrm{C}, 5\right.$ weeks) or immobilization stress adaptation ( $3 \mathrm{~h}$ daily, $25^{\circ} \mathrm{C}, 5$ weeks) caused enhanced NO activity in the basal condition in comparison with the control. We suggest that $\mathrm{NO}$ is involved in enhancement of the thermogenic functions of BAT in rats. [Japanese Journal of Physiology, 50, 337-342, 2000]

Key words: $\quad$ brown adipose tissue, nitric oxide, in vitro oxygen consumption, nonshivering thermogenesis.

Brown adipose tissue (BAT) is a thermogenic organ and its thermogenesis is indispensable when nonshivering thermogenesis is the main source of heat for body temperature regulation in mammals. Exposure of animals to a cold ambient temperature activates BAT, enhancing nonshivering thermogenesis to maintain a constant body temperature. Daily immobilization stress for several hours over several weeks in rats also activates the BAT function, and when these animals are exposed to a cold ambient temperature, they show an enhanced nonshivering thermogenic capacity, a phenomenon which is termed as cross adaptation [1-4]. Both cold exposure and repetitive immobilization stress may stimulate the sympathetic nervous system, initiating BAT activities responsible for the enhancement of nonshivering thermogenesis.

Blood flow perfusing BAT determines the thermogenic activity of the tissue. When the rats are exposed to cold or injected with the sympathetic nerve transmitter noradrenaline, the tissue is perfused with more blood to meet the increased metabolic demand. This increase in BAT blood flow ceases if the rats are co- injected with $\mathrm{N}^{\omega}$-nitro-L-arginine methyl ester (LNAME; a nitric oxide synthase inhibitor), implying a role for nitric oxide (NO) in the regulation of BAT blood flow [5]. This finding justified further investigation to explore the role of NO in BAT nonshivering thermogenesis. Subsequently, we reported that chronic treatment with L-NAME decreases the nonshivering thermogenic capacity of rats. The L-NAME-treated rats develop hypothermia on acute exposure to a cold ambient temperature and do not show any response to noradrenaline that normally increases oxygen consumption in vivo [6]. The thermogenic capacity of BAT isolated from these rats, as estimated by DNA content and in vitro oxygen consumption, is also found to be suppressed. In these previous studies, we adopted pharmacological means to suppress the NO synthase, but did not show any firm evidence of NO synthesis in BAT. In addition, it is not known if the physiological conditions that are known to enhance adaptive thermogenesis would enhance the capacity for NO synthesis in BAT. In this study, therefore, we addressed the question of firm evidence of $\mathrm{NO}$ in BAT

Received on February 23, 2000; accepted on April 27, 2000

Correspondence should be addressed to: Akihiro Kuroshima, Department of Physiology I, Asahikawa Medical College, Midorigaoka Higashi 2-1-1-1, Asahikawa, 078-8510 Japan. Tel.: +81-166-68-2322, Fax: +81-166-68-2329, E-mail: akihiro@asahikawa-med.ac.jp 
and the effects of cold acclimation and repetitive immobilization stress adaptation on NO in BAT in relation to the thermogenic capacity of BAT.

\section{MATERIALS AND METHODS}

Animals. Male Wistar rats were used in the experiments. They were obtained from Shizuoka Laboratory Animal Center, Hamamatsu, Japan. The rats were 7 weeks old when they were purchased and were kept in our animal laboratory for 1 week before grouping them for the experiments. They were housed in wire cages (three to five per cage) with free access to food (laboratory rat biscuits; Oriental MF, Oriental Yeast Co., Ltd., Tokyo, Japan) and tap water. Seven rats were housed in a cold room for 5 weeks for cold acclimation (CA). The temperature of the cold room was maintained at $5 \pm 1{ }^{\circ} \mathrm{C}$. Another group of seven rats were housed in a warm room $\left(25 \pm 1^{\circ} \mathrm{C}, 50 \%\right.$ relative humidity) and subjected to $3 \mathrm{~h}$-immobilization stress every day for 5 weeks using a wooden board and wire mesh for immobilization stress adaptation (ISA) (1). A group of 12 rats that were the control for the CA and ISA experiments were housed in the warm room. The rats were sacrificed by decapitation and the interscapular BAT was taken out, carefully separated from other tissues (such as muscles, large blood vessels, white adipose tissue) and the wet weight of the tissue was measured. The experimental protocol was approved by the Institutional Animal Care and Use Committee and complies with the laws of Japan.

In vitro oxygen consumption. BAT was carefully diced (ca. 1-mm $\mathrm{mm}^{3}$ blocks) and kept in a plastic vial containing $8 \mathrm{ml}$ of air-saturated Krebs-Ringer phosphate buffer (pH 7.4) at $37^{\circ} \mathrm{C}$ under slow shaking. The buffer contained the following $(\mathrm{mmol} / l): 120$ $\mathrm{NaCl}, 4.8 \mathrm{KCl}, 1.3 \mathrm{CaCl}_{2}, 1.2 \mathrm{MgSO}_{4}, 3 \mathrm{NaH}_{2} \mathrm{PO}_{4}$, and $12.7 \mathrm{Na}_{2} \mathrm{HPO}_{4}$. The buffer also contained glucose at $5 \mathrm{mmol} / \mathrm{l}$ and $4 \%$ bovine serum albumin (Armour Co., Fraction V, dialyzed for $48 \mathrm{~h}$ through cellulose membrane against Krebs-Ringer phosphate buffer, $\mathrm{pH}$ 7.4, to remove fatty acids). After two to three hours, a portion of the tissue (about $25 \mathrm{mg}$ ) was transferred to a magnetically stirred metabolic chamber having a temperature of $37^{\circ} \mathrm{C}$ and containing $2 \mathrm{ml}$ of the same air-saturated buffer for measurement of oxygen consumption. In the case of oxygen consumption of tissue slices, results with phosphate buffer are reported not to differ significantly from those with bicarbonate buffer [7]. In the case of the BAT blocks we used in this study, these two buffers were found not to differ significantly (unpublished observation). The chamber was closed, and oxygen consumption was measured by a Clark electrode (Rank Brothers, Cambridge, UK). The basal oxygen consumption was measured for $5 \mathrm{~min}$. After this, noradrenaline [(-)-Arterenol bitartrate salt (Sigma)] was added with a Hamilton syringe through a small hole in the cover of the chamber. The concentration of noradrenaline in the chamber was $6 \mu \mathrm{M}$, and this concentration has been shown to produce maximal stimulation of BAT from $25^{\circ} \mathrm{C}$ acclimated rats [8]. The rate of oxygen consumption of the electrode itself in the presence of $2 \mathrm{ml}$ buffer over a period of $10 \mathrm{~min}$ was measured routinely before the tissue blocks were added. The buffer initially contained $217 \mathrm{nmol} \mathrm{O}_{2} / \mathrm{ml}$.

Nitrite and nitrate assay. Diced BAT was incubated for $50 \mathrm{~min}$ in the metabolic chamber with or without noradrenaline in the medium as described above. Then, the medium was collected for nitrite assay using $\mathrm{NO}_{2} / \mathrm{NO}_{3}$ assay kit-C (Dojindo Laboratories, Japan). This assay method is based on a diazotization reaction producing azo compounds from sulfanilamide with nitrite and 1-naphthylethylenediamine. The absorbance of the coloured azo compound was measured at the wavelength of $540 \mathrm{~nm}$ by use of a microplate reader. Nitrate was first converted to nitrite enzymatically before assay. The nitrate reductase and enzyme co-factor are included in the kit. Figure 1 shows a representative nitrite standard reference curve for the same buffer medium we used in the experiments. NO production in the buffer medium was estimated by measuring nitrite and nitrate as they are stable and non-volatile breakdown products of NO.

Data analysis. Data were expressed as the mean \pm SE. The significance of differences between the groups was analyzed using analysis of variance (ANOVA) followed by Scheffe's $F$-test, Fisher's protected least-significant difference test or the Mann

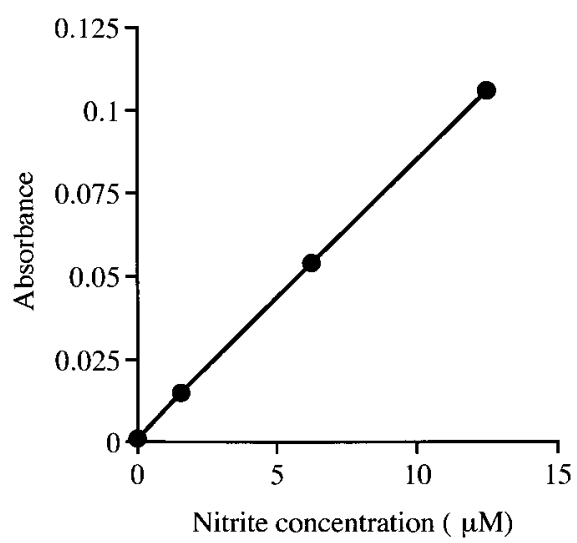

Fig. 1. Representative nitrite standard reference curve. Assays were performed using nitrite standard in the Krebs-Ringer phosphate-albumin buffer used in the experiments. 
Whitney $U$-test when suitable. When linear regression analysis was performed, Student's $t$-test was used to determine whether the mean slope deviated significantly from 0 . We considered differences significant at $p<0.05$.

\section{RESULTS}

\section{Body weight and BAT weight}

Rats were divided into three groups by matching their body weights. The increase in body weight was smaller in the CA and ISA groups than in the control group (Table 1). The BAT weight was larger in the CA and ISA groups than in the control group (Table 1). These results reflected cold acclimation and immobilization stress adaptation $[1,9]$. Agreeing with previous reports [1,9], the BAT weight in the CA group was larger than that in the ISA group.

\section{In vitro oxygen consumption}

The results of in vitro oxygen consumption are summarized in Fig.2. The basal in vitro oxygen con-

Table 1. Effects of cold acclimation and repetitive immobilization stress adaptation on body weight and interscapular BAT weight.

\begin{tabular}{llll}
\hline \multirow{2}{*}{ Group } & \multicolumn{2}{c}{ Body weight $(g)$} & \\
\cline { 2 - 3 } & Initial & \multicolumn{1}{c}{ Final } & \\
& & & \\
& & & \\
Control & $209 \pm 2$ & $300 \pm 8$ & $247 \pm 19$ \\
Cold & $211 \pm 2$ & $273 \pm 5^{\star}$ & $525 \pm 26^{\star \star \star}$ \\
Immobilization & $204 \pm 6$ & $251 \pm 10^{\star \star \star}$ & $325 \pm 15^{\star *, \#}$ \\
\end{tabular}

Cold, cold-acclimated rats; Immobilization, repetitive immobilization stress-adapted rats. ${ }^{*} p<0.05, \quad{ }^{* *} p<0.01$, ${ }^{\star * *} p<0.001$ vs. control group. ${ }^{\#} p<0.0001$ vs. cold-acclimated group. sumption as expressed per milligram of BAT was larger in the ISA group than in the control group (Fig. $2 \mathrm{~A})$. The basal in vitro oxygen consumption in the CA group was not significantly different from the control group. Administration of noradrenaline increased the oxygen consumption of BAT from the basal levels in the control and ISA groups. Noradrenaline administration did not significantly change the oxygen consumption from the basal level in the CA group. The oxygen tension in the chamber declined over time. Figure $2 \mathrm{~B}$ shows the decline in oxygen tension in $\mu \mathrm{mol} l^{-1}$ (mean of the lowest to mean of the highest at the indicated time-range) while measuring oxygen consumption in the control rats. The noradrenalinestimulated maximum oxygen consumption was recorded at 5-10 min at an oxygen tension of $127-$ $166 \mu \mathrm{M}$ in the control group. After that, the rate of oxygen consumption declined to near the basal level. The final oxygen tension in the chamber was 75$97 \mu \mathrm{M}$ (Fig. 2B). As the total oxygen consumption in the ISA was larger, the oxygen tension in the chamber declined from the initial $217 \mu \mathrm{M}$ to a final $34 \mu \mathrm{M}$ (not shown). As the total oxygen consumption in the CA was smaller, the oxygen tension in the chamber declined from the initial $217 \mu \mathrm{M}$ to a final $146 \mu \mathrm{M}$ (not shown).

\section{Nitrite and nitrate}

The results of the nitrite and nitrate assay are shown in Fig. 3. The basal production of nitrite plus nitrate $\left(\mathrm{NO}_{x}\right)$ as expressed per milligram of BAT was larger in the CA $(3.0 \pm 0.33 \mathrm{pmol} / \mathrm{mg} / \mathrm{min}, p<0.01)$ and ISA $(3.5 \pm 0.66 \mathrm{pmol} / \mathrm{mg} / \mathrm{min}, p<0.001)$ groups than in the control group $(1.2 \pm 0.19 \mathrm{pmol} / \mathrm{mg} / \mathrm{min})$. Administration of noradrenaline increased the production of $\mathrm{NO}_{x}$ from the basal level in the control group. Noradrenaline administration did not significantly change the
Fig. 2. A: Basal oxygen consumption of brown adipose tissue (BAT) and the maximum oxygen consumption after noradrenaline stimulation. Cold, coldacclimated group; Immobilization, immobilization stress-adapted group. B: Basal and the rate of oxygen consumption of BAT in the control group at various times after noradrenaline stimulation. The averages of the lowest and highest oxygen tensions ( $\mu \mathrm{M})$ in the chamber at each time are indicated. $\quad{ }^{*} p<0.01, \quad{ }^{* *} p<0.001$ vs. basal oxygen consumption of the same group. ${ }^{\#} p<0.001$ vs. control group. ${ }^{a} p<0.0001$ vs. cold-acclimated group.
B

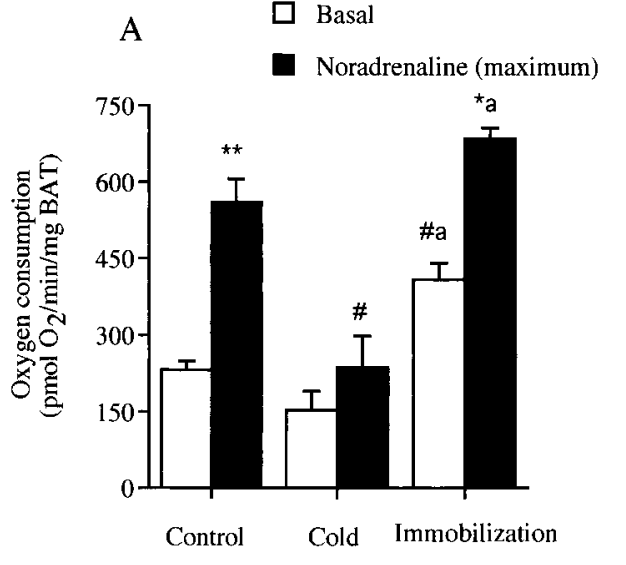



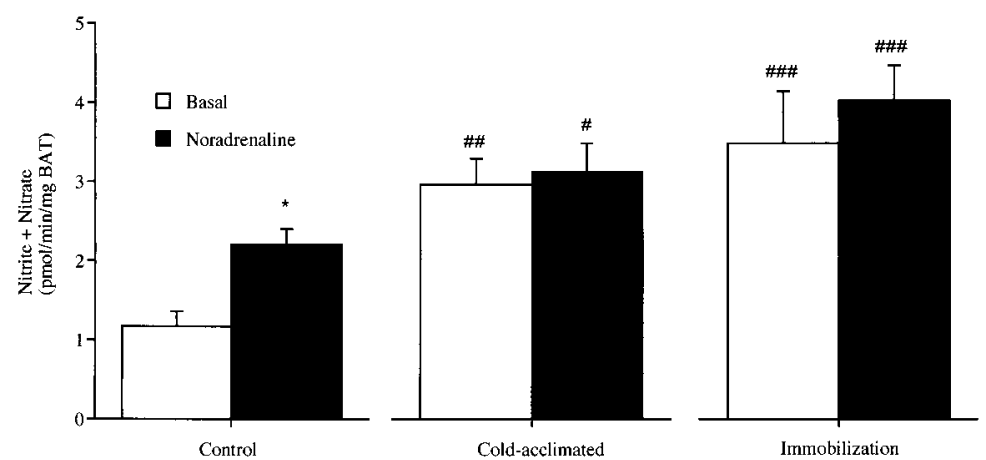

Fig. 3. Basal and noradrenaline-stimulated production of nitrite and nitrate in the incubation medium for brown adipose tissue respiration. ${ }^{\star} p<0.01$ vs. basal value of the same group. ${ }^{\#} p<0.05$, \#\# $p<0.01$, \#\#\# $p<0.001$ vs. control group.

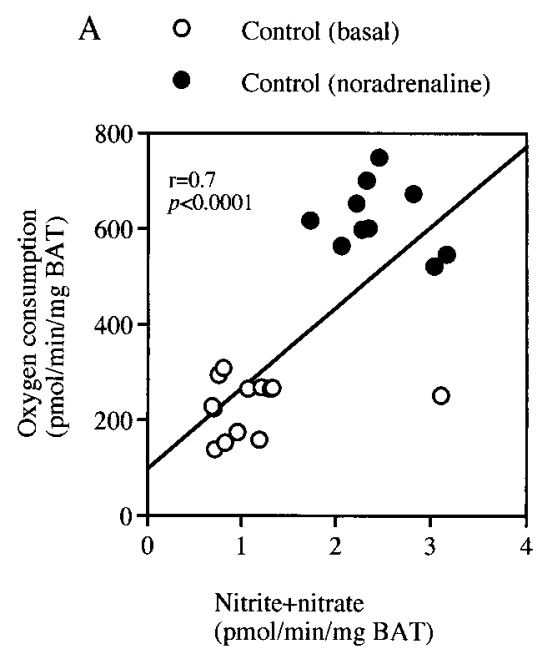

production of $\mathrm{NO}_{x}$ from the basal levels in the $\mathrm{CA}$ and ISA groups. The noradrenaline-stimulated $\mathrm{NO}_{x}$ levels were larger in the CA $(3.1 \pm 0.36 \mathrm{pmol} / \mathrm{mg} / \mathrm{min}, p<$ $0.05)$ and ISA $(4.0 \pm 0.44 \mathrm{pmol} / \mathrm{mg} / \mathrm{min}, p<0.001)$ groups than in the control group $(2.2 \pm 0.20 \mathrm{pmol} /$ $\mathrm{mg} / \mathrm{min}$ ).

\section{Regression analysis}

Administration of noradrenaline increased the $\mathrm{NO}_{x}$ production and oxygen consumption of BAT from the basal level in the control group. A regression analysis showed a correlation between $\mathrm{NO}_{x}$ and oxygen consumption (Fig. 4A). The basal level of $\mathrm{NO}_{x}$ and the basal level of oxygen consumption were larger in the ISA group than in the control group. Another regression analysis showed a correlation between basal $\mathrm{NO}_{x}$ and basal oxygen consumption in these groups (Fig. 4B). The basal level of $\mathrm{NO}_{x}$ was larger in the $\mathrm{CA}$ group than in the control group, but did not correlate with oxygen consumption (not shown).

\section{DISCUSSION}

We demonstrated here that small tissue blocks of freshly collected BAT from rats produced $\mathrm{NO}_{x}$ when they were incubated in a metabolic chamber for in vitro assay of oxygen consumption. This is firm evidence of NO activity in BAT, as there is no other source of $\mathrm{NO}_{x}$ in the incubation medium. This also confirms previous findings suggesting that BAT produces NO [6,10-13]. Furthermore, this study showed that cold acclimation and repetitive immobilization stress, which are known to enhance the thermogenic capacity of BAT $[1,3]$, enhanced the production of $\mathrm{NO}_{x}$ in the basal condition. Noradrenaline stimulation caused an increase in $\mathrm{NO}_{x}$ production in warm-acclimated control rats. These findings indicate that NO may be involved in enhancement of the thermogenic function of BAT in rats.

It is known that chronic exposure of rats to a cold ambient temperature or to repetitive immobilization stress discharges sympathetic signals to BAT, activating the tissue for nonshivering thermogenesis. The control rats are considered to have less active BAT. The elevated basal level of $\mathrm{NO}_{x}$ in the ISA and the noradrenaline-stimulated level in the control rats correlated with in vitro oxygen consumption (Fig. 4). These results suggest that NO is active in BAT as a signal molecule and enhances the thermogenic capacity of BAT. It is, however, observed that noradrenaline increased in vitro oxygen consumption from the basal level significantly, but not $\mathrm{NO}_{x}$ production in the ISA 
group. The exact cause of the disparity is not clear in this study. Noradrenaline administration did not increase $\mathrm{NO}_{x}$ production from the basal level in the CA group either.

The in vitro oxygen consumption as expressed per milligram of BAT was elevated in the ISA group in comparison with the control rats (Fig. 2) as previously reported [3]. In contrast, in vitro oxygen consumption was not elevated in the CA group as previously reported [2], although BAT in the CA group undoubtedly had elevated activity and capacity for nonshivering thermogenesis [2]. The capacity of BAT for nonshivering thermogenesis is a function of the number of brown adipocytes, the number of mitochondria in adipocytes, their mitochondrial protein content, and the concentration of uncoupling protein in the mitochondria. The CA rats show elevated levels of these parameters [14]. NO is involved in the regulation of some of these parameters in the CA group as indicated by the evidence that L-NAME treatment inhibited hyperplasia induced by cold exposure and that Larginine (NO precursor) caused hyperplasia of BAT [6]. This study, showing that the CA group had an enhanced basal level of $\mathrm{NO}_{x}$ in BAT, further implies the relation between $\mathrm{NO}$ and thermogenic functions, although the in vitro oxygen consumption of BAT was not increased. This result, that the in vitro oxygen consumption in the CA group was not increased, is in agreement with previous studies on tissue blocks $[2,9]$ and isolated brown adipocytes $[15,16]$.

$\mathrm{NO}$ is produced from L-arginine by NO synthase and acts as a messenger molecule mainly by stimulating guanylate cyclase. In a previous study, we demonstrated that noradrenaline-stimulated in vitro oxygen consumption in warm-acclimated rats is inhibited by the addition of methylene blue (guanylate cyclase inhibitor) to the medium [6]. In this study, we further demonstrated that noradrenaline-stimulated oxygen consumption is related to noradrenaline-stimulated $\mathrm{NO}_{x}$ release in the warm-acclimated control group. It is, therefore, suggested that a NO-cGMP pathway is involved in the regulation of BAT thermogenesis.

Besides guanylate cyclase, NO has an affinity to other heme groups such as cytochrome c oxidase. The NO-mediated inhibition of respiration (the rate of oxygen consumption), as shown by the experiments on isolated mitochondria, is suggested to be due to NO functioning as an alternative substrate for cytochrome c oxidase [17-21]. This inhibition is reversible and depends on oxygen tension and NO concentration. The lower the oxygen tension is, the higher the inhibitory action of NO. Although we measured the respiration of BAT cells in this study, it is neces- sary to evaluate whether there is any possibility of NO influencing in vitro oxygen consumption by binding with cytochrome c oxidase. In this study, about $25 \mathrm{mg}$ of BAT suspended in $2 \mathrm{ml}$ of buffer was incubated in the metabolic chamber for oxygen consumption. We calculated that the maximum accumulation of $\mathrm{NO}_{x}$ per minute in the metabolic chamber ranges from 28 to $50 \mathrm{nM}$, which is derived from 28 to $50 \mathrm{nM}$ NO. As NO has a very short half life of less than $1 \mathrm{~min}$, and if we consider that it takes about 2 min for the total disappearance of $\mathrm{NO}$ once produced, the level of NO in the chamber will be a little more than this value. This concentration of NO may inhibit oxygen consumption at a very low oxygen tension [17, 18,22]. But, for half-inhibition of respiration at an oxygen tension of around $200 \mu \mathrm{M}$ (near the oxygen tension in the 1sthalf of noradrenaline stimulation in our experiment), the NO concentration in the chamber should be more than 8 times higher as reported in the experiments of mitochondrial preparation [18]. In agreement with this observation, we found that noradrenaline stimulation increased oxygen consumption (respiration) during the first 10 min and reached a peak, implying that NOmediated inhibition of respiration was not predominant at this phase. As oxygen was being consumed in the closed system, the oxygen tension in the system declined during this time, increasing the possibility that NO functions as an inhibitor of mitochondrial respiration. This may be the cause for the rapid decline of oxygen consumption by BAT after reaching the peak, otherwise the peak should have plateaued as the incubation medium still contained noradrenaline (Fig. 2B).

On the other hand, in vitro oxygen consumption of BAT in the CA group was smaller than that in the other two groups and did not respond to noradrenaline. However, as mentioned earlier, this result cannot be reconciled with the fact that cold-acclimation enhances the thermogenic activity and capacity of BAT. The mitochondria of brown adipocytes are mainly coupled in warm-acclimated rats, but become uncoupled due to acute cold exposure or cold-acclimation enhancing the thermogenic capacity $[14,23,24]$. It has been suggested that cytochrome oxidase has evolved from the enzymes of anaerobic respiration $[25,26]$. Brown adipocyte mitochondria have cytochrome oxidase at the terminal site of the respiratory chain. As an alternative substrate for cytochrome c oxidase, NO functions as an electron acceptor instead of $\mathrm{O}_{2}$, producing $\mathrm{N}_{2} \mathrm{O}$ and $\mathrm{H}_{2} \mathrm{O}$ [20,21]. This may bypass the detection of NO release by measuring $\mathrm{NO}_{x}$. We found no change in the $\mathrm{NO}_{x}$ production with noradrenaline stimulation in the $\mathrm{CA}$ group. If this al- 


\section{S. K. SAHA and A. KUROSHIMA}

ternative substrate reaction ( $\mathrm{NO}$ instead of $\mathrm{O}_{2}$ ) produces heat in BAT, the enigma that BAT produces heat in vitro but consumes less oxygen would be explained.

We conclude that BAT produces NO and enhanced NO activity is related to the enhanced activity and capacity of BAT for nonshivering heat production in rats.

S. K. Saha is supported by the Japan Society for the Promotion of Science under the program of postdoctoral fellowships for foreign researchers.

\section{REFERENCES}

1. Kuroshima A, Habara Y, Uehara A, Murazumi K, Yahata $\mathrm{T}$, and Ohno T: Cross adaptation between stress and cold in rats. Pflüger Arch Eur J Physiol 402: 402-408, 1984

2. Kuroshima A: Brown adipose tissue thermogenesis as physiological strategy for adaptation. Jpn J Physiol 43: 117-139, 1993

3. Nozu T, Okano S, Kikuchi K, Yahata T, and Kuroshima A: Effect of immobilization stress on in vitro and in vivo thermogenesis of brown adipose tissue. Jpn J Physiol 299-308, 1992

4. Kuroshima A, Ohinata H, Kikuchi-Utsumi K, Saha SK, Gao B, Hashimoto M, and Ohno T: Brown adipose tissue nonshivering thermogenesis in stressful states. In: Thermotherapy: Principles and Practice-Applications in Neoplasia, Inflammation, and Pain, ed. Kosaka M, Sugahara T, Schmidt KL, and Simon E, Springer-Verlag Inc, Tokyo, in press

5. Nagashima $T$, Ohinata $H$, and Kuroshima A: Involvement of nitric oxide in noradrenaline-induced increase in blood flow through brown adipose tissue. Life Sci 54: 17-25, 1994

6. Saha SK, Ohinata $H$, and Kuroshima A: Effects of acute and chronic inhibition of nitric oxide synthase on brown adipose tissue thermogenesis. Jpn J Physiol 46: 375 382, 1996

7. DeLuca HF and Cohen PP: Preparation of tissues and enzymes. In: Manometric Techniques, ed. Umbreit WW, Burris $\mathrm{RH}$, and Stauffer JF, Burger, Mineapolis, pp 131133, 1964

8. Kuroshima A, Ohno T, and Yahata T: Effect of low-iron diet on in vitro thermogenesis of brown adipose tissue. Jpn J Biometeorol 27: 27-31, 1990

9. Kuroshima A, Yahata T, and Ohno T: Comparison of in vitro thermogenesis of brown adipose tissue in coldacclimated rats and guinea pigs. J Therm Biol 16: 109114,1991

10. Kuroshima A, Nagashima $T$, Iwamoto J, Ohinata $H$, Saha SK, and Yoshida T: Messenger molecule nitric oxide in cold - with special reference to brown adipose tissue. In: Body Temperature and Metabolism, ed. Na- gasaka T and Milton AS, IPEC (International Press Editing Centre Incorporation), Tokyo, pp 207-209, 1995

11. Saha SK, Ohno T, Ohinata H, and Kuroshima A: Effects of nitric oxide synthase inhibition on phospholipid fatty acid composition of brown adipose tissue. Jpn J Physiol 47: 477-480, 1997

12. Nisoli E, Tonello C, Briscini L, and Carruba MO: Inducible nitric oxide synthase in rat brown adipocytes: implications for blood flow to brown adipose tissue. Endocrinology 138: 676-682, 1997

13. Morley JE, Alshaher MM, Farr SA, Flood JF, and Kumar VB: Leptin and neuropeptide $Y$ (NPY) modulate nitric oxide synthase: further evidence for a role of nitric oxide in feeding. Peptides 20: 595-600, 1999

14. Trayhurn $P$ and Milner RE: A commentary on the interpretation of in vitro biochemical measures of brown adipose tissue thermogenesis. Can J Physiol Pharmacol 67: 811-819, 1989

15. Unelius L, Bronnikov G, Mohell N, and Nedergaard J: Physiological desensitization of beta 3-adrenergic responses in brown fat cells: involvement of a postreceptor process. Am J Physiol 265: C1340-C1348, 1993

16. Unelius L, Mohell N, and Nedergaard J: Cold acclimation induces desensitization to adenosine in brown fat cells without changing receptor binding. Am J Physiol 258: C818-C826, 1990

17. Okada S, Takehara Y, Yabuki M, Yoshioka T, Yasuda T, Inoue $\mathrm{M}$, and Utsumi $\mathrm{K}$ : Nitric oxide, a physiological modulator of mitochondrial function. Physiol Chem Phys Med NMR 28: 69-82, 1996

18. Brown GC: Nitric oxide and mitochondrial respiration. Biochim Biophys Acta 1411: 351-369, 1999

19. Kroncke KD, Fehsel K, and Kolb-Bachofen V: Nitric oxide: cytotoxicity versus cytoprotection-how, why, when, and where? Nitric Oxide 1: 107-120, 1997

20. Cassina A and Radi R: Differential inhibitory action of nitric oxide and peroxynitrite on mitochondrial electron transport. Arch Biochem Biophys 328: 309-316, 1996

21. Borutaite $\vee$ and Brown GC: Rapid reduction of nitric oxide by mitochondria, and reversible inhibition of mitochondrial respiration by nitric oxide. Biochem $\mathrm{J} 315$ : 295-299, 1996

22. Koivisto A, Matthias A, Bronnikov G, and Nedergaard $\mathrm{J}$ : Kinetics of the inhibition of mitochondrial respiration by NO. FEBS Lett 417: 75-80, 1997

23. Nicholls DG and Locke RM: Thermogenic mechanisms in brown fat. Physiol Rev 64: 1-64, 1984

24. Himms-Hagen J: Brown adipose tissue thermogenesis and obesity. Prog Lipid Res 28: 67-115, 1989

25. Castresana J, Lubben M, Saraste M, and Higgins DG: Evolution of cytochrome oxidase, an enzyme older than atmospheric oxygen. EMBO J 13: 2516-2525, 1994

26. Saraste $M$ and Castresana J: Cytochrome oxidase evolved by tinkering with denitrification enzymes. FEBS Lett 341: 1-4, 1994 